\title{
Effects of Contingent and Non-Contingent Cocaine on Drug-Seeking Behavior Measured Using a Second-Order Schedule of Cocaine Reinforcement in Rats
}

\author{
Athina Markou, Ph.D., Mercedes Arroyo, B.A., and Barry J. Everitt, Ph.D.
}

Rats were trained to respond with intravenous cocaine as the reinforcer under a fixed interval 15-min schedule, during which conditioned stimuli paired with cocaine were presented contingent on completion of a fixed ratio of 10 responses (i.e., second-order schedule of reinforcement). The effects of contingent and noncontingent cocaine were investigated. The results show that pretreatment with noncontingent (i.e., experimenter-administered) cocaine led to a satiation-like effect that was reflected in decreased numbers of responses and a tendency for an increased latency to initiate responding when the doses of cocaine administered were similar to or higher than the training/ maintenance dose of cocaine. By contrast, noncontingent administration of cocaine doses lower than the training/ maintenance dose, and response-contingent cocaine administration, led to increased drug-seeking behavior, as reflected in increased numbers of responses. The present data indicate that at least two factors determine whether administration of cocaine would lead to drug-seeking behavior: whether the cocaine administration is contingent or noncontingent, and the relative magnitude of the cocaine dose administered in relation to the training/maintenance dose of cocaine. [Neuropsychopharmacology 20:542555, 1999] (C) 1999 American College of Neuropsychopharmacology. Published by Elsevier Science Inc.
KEY WORDS: Cocaine; Psychomotor stimulant;

Self-administration; Second-order schedule; Contingency;

Expectation; Drug-taking; Drug-seeking; Craving;

Conditioned stimuli; Priming; Animal model; Rat

Drugs of abuse, such as psychomotor stimulants, are powerful reinforcers in animals, including humans (for reviews, see Fischman et al. 1983; Bozarth 1987; Johanson and Fischman 1989; Liebman and Cooper 1989; Markou et al. 1993). In humans, these reinforcing properties of

From the Department of Neuropharmacology (AM), The Scripps Research Institute, La Jolla, California; and the Department of Experimental Psychology (MA, BJE), University of Cambridge, Cambridge, United Kingdom.

Address correspondence to: Athina Markou, Ph.D., Department of Neuropharmacology, CVN-7, The Scripps Research Institute, 10550 North Torrey Pines Rd., La Jolla, CA 92037.

Received April 15, 1998; revised July 20, 1998; accepted August 3, 1998 drugs maintain extended sequences of behavior that can be described as drug-seeking behavior because they comprise purchase, preparation, and administration of the drug. Further, clinical observations indicate that stimuli that have been previously associated with the reinforcing properties of drugs [i.e., conditioned stimuli, (CSs); see below] play an important role in drugseeking and drug-taking behavior in humans (Wikler 1971; Levine 1974; O’Brien et al. 1984; 1990; 1992; Ludwig 1986; McLellan et al. 1986; Childress et al. 1986; 1988). Thus, the study of extended sequences of drugseeking behavior in animals, and in particular, drugseeking behavior that is influenced by the presentation of drug-associated CSs, promises to provide valuable insights into the environmental and neurobiological factors that modulate drug-seeking and drug-taking behavior (Markou et al. 1993). 
One behavioral paradigm that has been used extensively to study drug-seeking behavior in both human (Mello and Mendelson 1985; Henningfield et al. 1988; Mello et al. 1990; Lamb et al. 1991) and nonhuman (Goldberg 1973; Goldberg and Tang 1977; Goldberg et al. 1981; Johanson 1982; Howell and Byrd 1991; Spear et al. 1991; Spealman et al. 1991; Mello et al. 1995; Negus et al. 1995) primates is a second-order schedule of reinforcement (for a review of this paradigm, see Markou et al. 1993). Recently, similar second-order schedules of drug reinforcement have been established in rats (Corrigall and Coen 1989; Ranaldi and Roberts 1996; Whitelaw et al. 1996; for extensive descriptions of the acquisition and maintenance of a second-order schedule of cocaine reinforcement in rats, see Arroyo et al., 1998), a species that more readily than primates, allows the investigation of the neural bases of behavioral phenomena, such as drug-seeking. An important aspect of such second-order schedules is that responding for the primary reinforcer is maintained for prolonged periods of time unconfounded by the pharmacological effects of the primary drug reinforcer. Moreover, such responding also depends upon presentation of previously neutral stimuli that have acquired secondary- or conditionedreinforcing properties through predictive associations with the primary drug reinforcer (Kelleher 1975; Kelleher and Goldberg 1977; Katz 1979; Goldberg et al. 1979; 1981; Goldberg and Gardner 1981; Carroll 1985; Spear and Katz 1991; Arroyo et al., 1998).

Investigating drug-seeking behavior uncontaminated by direct pharmacological effects of the selfadministered drug is important because such conditions closely resemble drug-seeking behavior in humans after a period of abstinence (i.e., resumption of drug-taking or relapse), and because it is conceivable that drug-seeking behavior in the presence of the acute drug effects is mediated by different neural mechanisms than drug-seeking behavior in the absence of these acute drug effects (Markou et al. 1993).

The present studies were therefore designed to investigate one aspect of the question of whether drugseeking behavior after acute cocaine administration is different from drug-seeking behavior before cocaine administration by examining the effects of contingent and noncontingent cocaine administration on performance under a second-order schedule of cocaine reinforcement in rats. Such investigations are also relevant in the context of experimental findings in humans, demonstrating that expectation (which also may be considered to be involved in contingent drug administration in animals) of a psychostimulant or alcohol effect enhanced the subjective positive effects of the drug in comparison to the subjective effects of the same drug dose when not anticipated (i.e., noncontingent) (Hull and Bond 1986; Laberg 1986; de Boer et al. 1993; Mitchell et al. 1996). The experimental designs used in the present studies allowed the investigation of the issue of "expectancy" in rat drug-seeking behavior by allowing animals to contingently administer cocaine and thus "expect/anticipate" cocaine's pharmacological effects. Finally, the present studies investigated the effects on drug-seeking behavior of two different doses of noncontingent cocaine, one being the training dose and the other being one third the training dose, and also whether the effects of noncontingent administration of these two cocaine doses on performance under the second-order reinforcement schedule habituated with repeated administration.

\section{METHODS}

\section{Subjects}

Male Lister hooded rats (Charles River Ltd., U.K.) weighing 320-360 $\mathrm{g}$ at the start of the experiment were housed in pairs under a 12-h light-dark cycle (lights off at 10:00 A.M.). Each animal received 20 g Purina lab chow / day at approximately 6:00 p.m., which was sufficient to maintain preoperative body weight and growth. Water was available ad libitum at all times, except during testing sessions. All training and testing took place during the dark phase of the light-dark cycle. Experiments were carried out in accordance with the United Kingdom 1986 Animals (Scientific Procedures) Act (Project License PPL 80/00684), and the Guide for the Care and Use of Laboratory Animals as adopted by the National Institutes of Health.

\section{Apparatus}

Training and testing took place in six operant chambers $(24 \times 20 \times 22 \mathrm{~cm}$; Campden Instruments Ltd., Loughborough, U.K.) housed inside ventilated sound- and light-attenuating enclosures. Each chamber contained two retractable levers (4 $\mathrm{cm}$ wide) within one wall, which extended $1.5 \mathrm{~cm}$ into the chamber, and were positioned $9 \mathrm{~cm}$ above the floor, $10 \mathrm{~cm}$ apart and $2.5 \mathrm{~cm}$ from the side walls. The force required to press each lever was approximately $0.12 \mathrm{~N}$. A circular stimulus light ( $2 \mathrm{~cm}$ in diameter) was positioned $3 \mathrm{~cm}$ above each lever and was illuminated by a 2.5-W, 24-V light bulb according to the experimental conditions (see below). During the testing session, the chamber was illuminated by a red 2.5-W, 24-V house light, which was positioned in the middle of the ceiling of the operant chamber. Each chamber was also equipped with a Razel infusion pump (Semat Technical Ltd., Herts, U.K.) that delivered infusions of cocaine through a single channel liquid swivel (Stoelting, IL) and wire-enclosed leads (Plastic One, VA). Experimental parameters and data collection were controlled by a microcomputer. 


\section{Surgery: Intravenous Catheterization}

Rats were anaesthetized with Avertin (10 g 99\% 2,2,2tribromo-ethanol; Sigma-Aldrich Co. Dorset, U.K.) and $5 \mathrm{mg}$ tertiary amyl alcohol diluted in $4.5 \mathrm{ml}$ phosphatebuffered saline (Dulbecco "A"; Unipath Ltd., Hampshire, U.K.) and $40 \mathrm{ml}$ absolute alcohol $(1 \mathrm{ml} / 100 \mathrm{~g}$ body weight intraperitoneally). Intravenous self-administration catheters were implanted into the right jugular vein of each rat. Catheters consisted of Silicon tubing (STHT-C-030-0 and STHT-C-020-0, Osteotec Ltd., U.K.) attached to a stainless steel guide cannula (C313G 5UP Semat Technical Ltd., Herts, U.K.) bent at a right angle, encased in dental cement (Simplex Rapid, Associated Dental Products Ltd., Wiltshire, U.K.) and anchored with a $2.3-\mathrm{cm}$ square of durable plastic mesh (Small Parts, FL). The tubing was passed subcutaneously from the animal's mid-capsular region to the right external jugular vein, where it was inserted and secured with suture thread. Animals were allowed a minimum of 5 days recovery from surgery before being given access to cocaine, during which time rats were flushed with $0.1 \mathrm{ml}$ of an antibiotic solution (Timentin $3.2 \mathrm{~g}: 200 \mathrm{~g}$ potassium clavalanate with $3 \mathrm{~g}$ ticarcillin; Beecham Research, Herts, U.K.; $65 \mathrm{mg}$ of Timentin was dissolved in $1 \mathrm{ml}$ saline). To ensure patency, catheters were flushed daily with approximately $0.1-0.3 \mathrm{ml}$ saline containing heparin (30 usp units/ml; CP Pharmaceuticals Ltd., Wrexham, U.K.). When not in use, catheters were capped with a short length of Tygon tubing (Altec 01-94-1554, Altevin Laboratory, Hants, U.K.), plugged with monofilament and covered with a stainless steel cap. Catheter patency was tested with Brietal Sodium (2.5\% methoexitone sodium, Lilly France SA, distributed by Animalcare Ltd., York, U.K.) whenever an animal not receiving drug treatment displayed self-administration behavior outside baseline performance. Animals with patent catheters exhibit pronounced loss of muscle tone within $2 \mathrm{~s}$ of intravenous injection of Brietal Sodium.

\section{EXPERIMENTAL PROCEDURES}

\section{Second-Order Schedule of Reinforcement for Cocaine: Training and Testing}

Before connecting the subjects to the self-administration leads, the experimenter ensured that the entire tubing was filled with cocaine solution up to the injector tip with no dead space. Rats were placed into the operant chambers, and the session was initiated by the experimenter pressing three times rapidly on one of the two levers that was thereby assigned as the active-drug lever for each subject. The illumination of the red house light signalled the initiation of the 2-h self-administration session. Half of the animals were assigned the right lever as the active-drug lever, and the other half were assigned the left lever in a counterbalanced way; lever assignments remained constant for each subject throughout the experiment. Rats were allowed to acquire intravenous cocaine self-administration under a continuous reinforcement schedule [i.e., FR1, which also can be formally described as a second-order schedule of the type (FR1:S)]. After the initiation of the session, depressions of the drug-active lever resulted in immediate extinction of the red house light and illumination of the white light above the active-drug lever for $20 \mathrm{~s}$. One second after the depression of the lever, the pump also was activated for $3.6 \mathrm{~s}$ delivering $0.1 \mathrm{ml}$ of cocaine hydrochloride solution $(0.25 \mathrm{mg}$ of cocaine/injection, calculated as the salt and dissolved in sterile saline; cocaine was obtained from McFarlan-Smith, Edinburgh, U.K.), and both levers were retracted for a total of $19 \mathrm{~s}$. Twenty seconds after the lever depression, the house light was again illuminated, the stimulus light was extinguished, and the levers were extended into the operant chamber. Responses on the inactive lever were recorded but had no programmed consequences, and, as such, they provided an index of basal levels of activity. Because there were very few responses, and often no responses, on the inactive levers during all phases of all experiments, inactive lever responses were not analyzed.

After acquisition of cocaine self-administration under the continuous reinforcement schedule, the schedule requirements were gradually increased to FR10 (FR1:S), and then to FR10 (FR10:S) during the 2-h daily sessions (see Arroyo et al., 1998, for further details on training rats on this second-order schedule of reinforcement). During this phase of training, whenever the subject earned a CS according to the schedule in effect, the stimulus light above the active lever was illuminated for $1 \mathrm{sec}$ and the house light was extinguished for the same period of time, but there was no retraction of the levers; this sequence of events constituted the CS. When the subjects reached the FR10 (FR2:S) stage and for all stages beyond, the session was terminated after the subject earned 10 injections or after $2 \mathrm{~h}$ had elapsed, whichever occurred first.

Finally, schedule requirements were changed to a Fixed Interval (FI) 15-min (FR10:S) schedule of reinforcement. It took approximately 4 weeks for subjects to train on this schedule and establish stable baseline performance. During this FI 15-min (FR10:S) schedule, subjects earned a cocaine injection and a light stimulus presentation (also associated with extinction of the house light and retraction of the two levers; timing of events exactly as described above for the FR1 schedule) when they completed 10 lever presses after the 15-min fixed interval elapsed. In addition, during the 15-min fixed interval, every 10th response on the active lever resulted in a 1-s presentation of the stimulus light and 1-s extinction of the house light, but there was no retraction of the levers (see Figure 1). After the schedule require- 
Performance on Second-Order Fixed-Interval Reinforcement Schedule for Cocaine after Various Non-Contingent IP Cocaine Injections

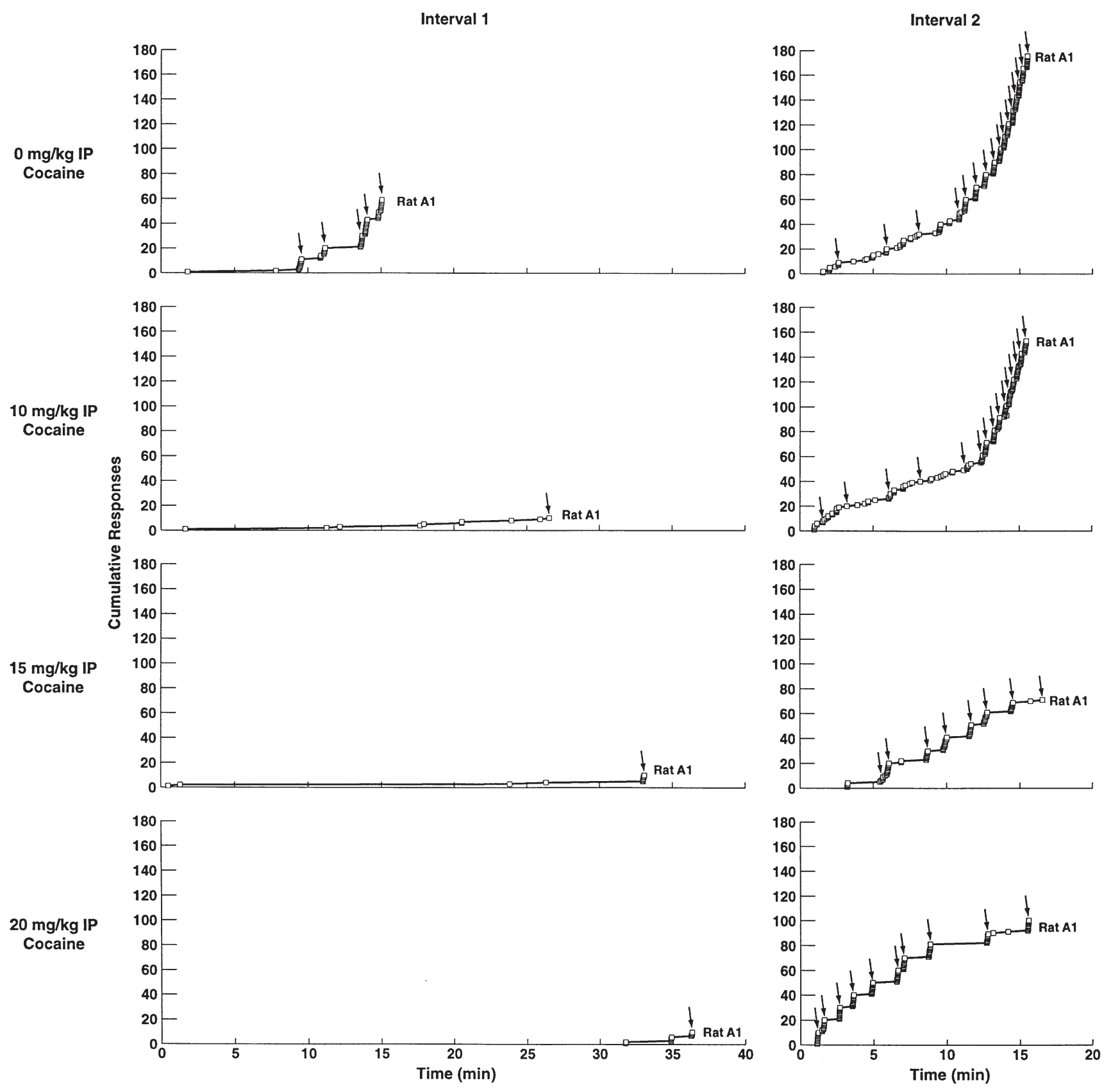

Figure 1. Individual rat's cumulative response records for cocaine on a F1 15-min (FR10:S) second-order reinforcement schedule during the first and second interval of the day after 0,10, 15 and $20 \mathrm{mg} / \mathrm{kg}$ of noncontingent (i.e., experimenteradministered) IP cocaine. Arrows indicate the time-points at which the subject earned a light stimulus presentation after completing the FR10 schedule for the light stimulus (CS). Note that the noncontingent IP injections of cocaine resulted in an increase in the latency to initiate responding and a decrease in the total number of responses emitted during the first interval compared to baseline performance after the noncontingent IP injection of saline $(0 \mathrm{mg} / \mathrm{kg}$ cocaine $)$. By contrast, noncontingent IP injections of cocaine had no effect on either the latency to initiate responding or the total number of responses emitted during the second interval. Under baseline conditions $(0 \mathrm{mg} / \mathrm{kg}$ cocaine), performance during the first interval of the day reflects drug-seeking behavior before the administration of any cocaine (i.e., animal in the undrugged state). Note the acceleration of responding and the resulting increase in total number of responses during interval 2 after the response-contingent self-administration of $0.25 \mathrm{mg} / \mathrm{kg}$ cocaine. 
ments were changed to the FI 15-min (FR10:S), subjects were allowed to earn a maximum of five cocaine injections during each daily session. The session was terminated when the subject earned five cocaine injections or when 2 h had elapsed, whichever occurred first. Under baseline conditions, all subjects readily completed the schedule requirements and earned five cocaine injections within approximately $95 \mathrm{~min}$, at which point the session was terminated (for details on the performance of rats under the FI second-order schedule of reinforcement described above during all five fixed intervals, see Arroyo et al., 1998). After stable performance on the FI 15-min (FR10:S) schedule was established (approximately $10-20 \%$ variation during three consecutive days), drug manipulations were initiated, as described below. For all four experiments described below, subjects were required to perform under the above described FI 15-min (FR10:S) second-order schedule of reinforcement to self-administer cocaine. It should be noted that noncontingent injections of cocaine, that are commonly administered to rats to facilitate acquisition of cocaine self-administration in other studies, were never administered to the rats used in the present experiments during any phase of training.

Several dependent measures can be derived from a subject's performance under a second-order schedule of reinforcement. In the present studies, the measures used were total number of responses emitted during a single fixed interval and latency to initiate responding, expressed in minutes and referring to the time that elapsed between the initiation of the session (or the interval) and the subject's first response on the activedrug lever.

Another measure frequently used in describing a subject's performance under second-order schedules of reinforcement is the index of curvature (Fry et al. 1960), which reflects the temporal pattern of responding. Indices of curvature were calculated and analyzed for all fixed interval responding in the present experiments. Nevertheless, many treatments in these studies delayed the initiation of responding beyond the duration of the fixed interval adapted, thereby greatly limiting the value of index of curvature measures. Thus, the index of curvature data are not presented here. Detailed descriptions of changes in the index of curvature measure during acquisition of the second-order schedule of cocaine reinforcement, and of the effects of self-administered cocaine on this measure, can be found in Arroyo et al. (1998).

Emphasis is given to data from the first injection interval because the primary interest was in cocaine-seeking behavior before any cocaine self-administration. Data from the second injection interval also are presented to allow direct comparisons between the effects of noncontingent experimenter-administered injections of cocaine with the effects of the same dose of cocaine contingently self-administered under the second-order schedule of reinforcement. Data from the third, fourth, and fifth interval were analyzed but not presented here because there were no statistically significant effects of any of the manipulations used on the subjects' performance during these later intervals. Further, there were no statistically significant differences between performance during the second interval and performance during the later intervals under baseline conditions or after the various experimental manipulations. Thus, the presentation of the first and second injection interval data depicts the rats' performance under second-order schedules of cocaine reinforcement adequately and efficiently, without detracting from the interesting effects seen only during the first interval.

\section{Experiment 1: Pretreatment with Noncontingent Cocaine (IP)}

After stable responding was established under the second-order schedule of reinforcement, animals $(n=4)$ were tested on three consecutive days (predrug baseline) after intraperitoneal (IP) injections of saline (10 min pretreatment) to habituate the rats to the injection procedure. Then, subjects were administered I.P. 0, 10, 15 and $20 \mathrm{mg} / \mathrm{kg}$ cocaine hydrochloride in an ascending dose order. These doses were selected because they were shown previously to enhance reward in rats, as assessed by the intracranial self-stimulation paradigm (Markou and Koob 1992). None of the manipulations used in the present studies had any long-term effects on performance, as indicated by return to baseline levels of responding the day after each manipulation in all experiments. At least $48 \mathrm{~h}$ elapsed between drug injections, and saline injections were administered to the rats before their daily self-administration sessions during those intervening days. After the administration of all cocaine doses, subjects were tested for an additional three days after saline injections (postdrug baseline). All drug-day data were expressed as percent change from the mean of the pre- and postdrug baseline responses and latencies to initiate responding. Expressing data as percent of baseline values reduced the betweensubject variability that is observed in the animals' performance under second-order schedules of reinforcement (Goldberg et al 1971; Johanson 1982).

\section{Experiment 2: Pretreatment with Noncontingent Cocaine (IV)}

Rats $(n=8)$ were placed in the operant chamber and immediately afterwards received a noncontingent intravenous (IV) cocaine injection, an identical dose to what they had been allowed to self-administer $(0.25 \mathrm{mg}$ of cocaine hydrochloride in $0.1 \mathrm{ml}$ saline). This noncontingent drug administration was delivered through the 
pump that was operated remotely by the experimenter through the computer. Immediately after this noncontingent injection, the session started, signalled by the extension of the two levers into the chamber and the illumination of the red house light.

\section{Experiment 3: Pretreatment with Contingent IV Cocaine Under a FR2 Schedule of Reinforcement}

Rats $(n=7)$ were placed in the operant chamber and allowed to self-administer a single injection of cocaine (0.25 mg/injection) under a FR2 schedule of reinforcement. Then, the second-order schedule came into effect, and subjects were allowed to self-administer cocaine under this second-order schedule similarly to all previous testing sessions. This FR2 schedule was selected because it allowed the contingent injection of cocaine with minimal response requirements, thus permitting comparisons of the effects of contingent cocaine self-administered under two schedules with different response requirements [i.e., FR2 versus FI 15 min (FR10:S)].

\section{Experiment 4: Pretreatment with Repeated Noncontingent IV Cocaine}

After stable baseline performance was observed under the second-order reinforcement schedule at the 0.25 $\mathrm{mg}$ /injection cocaine dose for at least three consecutive days, rats $(n=8)$ were noncontingently administered IV $0.25 \mathrm{mg}$ of cocaine hydrochloride immediately before the initiation of their daily session for 3 consecutive days, similarly to the procedure described under Experiment 2 . Then, rats continued to be tested under baseline conditions until stable baseline performance was again observed (i.e., 5 to 7 days). Subsequently, rats $(n=6)$ were again administered noncontingently 0.083 $\mathrm{mg}$ (one third of the training dose) of IV cocaine hydrochloride immediately before the initiation of their daily session for 3 consecutive days.

\section{DATA ANALYSES}

For Experiment 1, pre- and postdrug baseline number of responses and latencies to initiate responding were compared with paired $t$-tests. Because there were no statistically significant differences in the subjects' baseline performance before and after the IP cocaine administrations, the means of the pre- and the post-baseline scores were used as the best estimates of the subjects' baseline performance. All drug-day data, including the $0 \mathrm{mg} / \mathrm{kg}$ dose, were expressed as percent change from those baseline scores. Data from Experiment 1 were analyzed with one-way within-subjects analyses of variance (ANOVAs), and statistically significant effects were analyzed further using Newman-Keuls compari- sons (Winer, 1971). Whenever the sphericity test (Dixon, 1992) indicated nonhomogeneity of variance ( $p$ $<.05)$, data were analyzed with the nonparametric Friedman ANOVA (Siegel 1956), and statistically significant effects were followed with posthoc nonparametric comparisons using the Wilcoxon matched-pairs signedranks test (Siegel 1956). In all cases where nonparametric statistics were used, similar results were also obtained with parametric statistical analyses. Only the nonparametric statistics are reported in these cases because these are the appropriate statistical tests for the specific data sets. Nevertheless, all data are presented in graphs as means \pm standard errors of the means to facilitate comparisons among data from different experiments. Even though reported statistical analyses on latencies to initiate responding for Experiment 1 were performed on percent values to be consistent with the reports of statistics on percent response numbers, raw latency values shown in minutes are listed in the results section for Experiment 1 to provide a clear representation of the subjects' performance under the various conditions. Statistical analyses on both raw and percent latency data provided identical results.

For Experiments 2, 3, and 4, raw (i.e., not percent of baseline) data were analyzed with one- or two-way repeated measures parametric or nonparametric ANOVAs and appropriate posthoc comparisons, similarly to what has been described above for Experiment 1. All data analyses were performed with the BMDP statistical package (Dixon, 1992). The level of significance was set at $p<.05$.

\section{RESULTS}

\section{Experiment 1: Pretreatment with Noncontingent Cocaine (IP)}

First Interval Data. An ANOVA $[\mathrm{F}(2,6)=11.86, p<$ $.01]$ on the descending part of the dose-response curve and Newman-Keuls comparisons indicated that noncontingent IP administration of 10 and $15 \mathrm{mg} / \mathrm{kg}$ of cocaine significantly reduced the number of responses compared to the $0 \mathrm{mg} / \mathrm{kg}$ dose $(p<.05)$ (see Figure 2). In addition, there was a statistically significant increase in the latency to initiate responding $\left(\mathrm{X}_{\mathrm{r} 2}=29, p<.01\right)$. Nevertheless, due to the large variability among subjects, posthoc Wilcoxon tests did not reveal any statistically reliable differences between the effects of $0 \mathrm{mg} / \mathrm{kg}$ (mean \pm SEM: $1.84 \pm 0.52 \mathrm{~min}$ ), and the effects of 10 $\mathrm{mg} / \mathrm{kg}$ (means $\pm \mathrm{SEM}: 5.41 \pm 1.93 \mathrm{~min}$ ) or $15 \mathrm{mg} / \mathrm{kg}$ (mean \pm SEM: $16.48 \pm 11.12 \mathrm{~min}$ ) cocaine on latencies. Comparison of the effects of 0 and $20 \mathrm{mg} / \mathrm{kg}$ (latency mean \pm SEM: $27.68 \pm 17.22 \mathrm{~min}$ ) cocaine on response numbers $[\mathrm{F}(1,3)=0.37, \mathrm{NS}]$ and latencies $[\mathrm{F}(1,3)=3.24$, NS indicated no statistically significant effects. 


\section{Non-Contingent IP Cocaine}

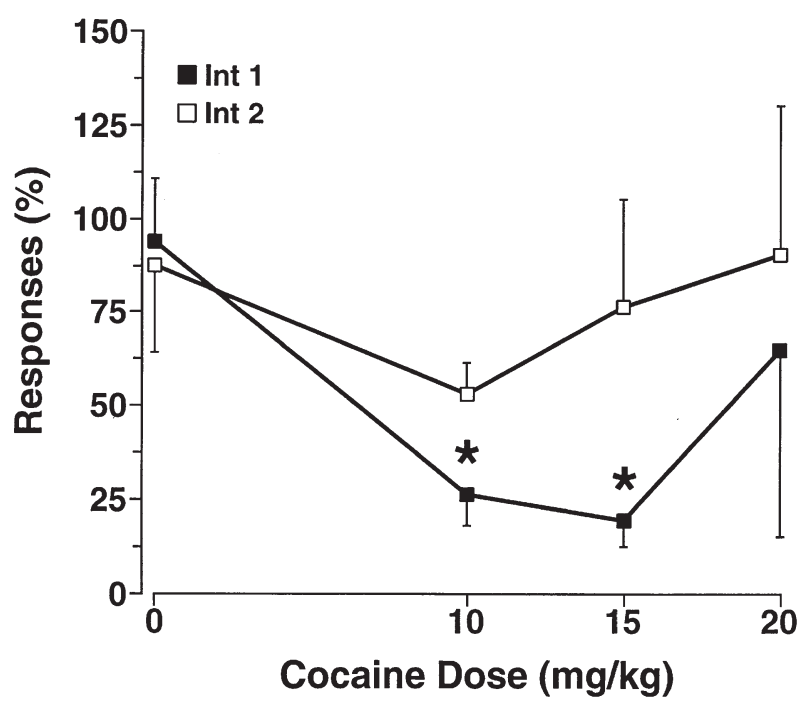

Figure 2. Pretreatment with noncontingent IP cocaine hydrochloride (10 and $15 \mathrm{mg} / \mathrm{kg}$ ) significantly decreased responses under a second-order reinforcement schedule for cocaine during the first, but not during the second, injection interval $(n=4)$. Asterisks indicate statistically significant differences from performance after the $0 \mathrm{mg} / \mathrm{kg}$ dose for the respective interval.

Second Interval Data. Repeated-measures ANOVAs indicated no statistically significant effects of IP cocaine administration on either response numbers $[\mathrm{F}(3,9)=$ $0.89, \mathrm{NS}]$ or response latencies $[\mathrm{F}(3,9)=0.65, \mathrm{NS}]$ for the second interval (see Figure 2). Mean \pm SEM latencies were $3.02 \pm 1.22 \mathrm{~min}$ after $0 \mathrm{mg} / \mathrm{kg}$ cocaine, $3.95 \pm$ $2.03 \mathrm{~min}$ after $10 \mathrm{mg} / \mathrm{kg}$ cocaine, $4.27 \pm 1.98 \mathrm{~min}$ after 15 $\mathrm{mg} / \mathrm{kg}$ cocaine, and $1.56 \pm 0.24 \mathrm{~min}$ after $20 \mathrm{mg} / \mathrm{kg}$ cocaine.

\section{Experiment 2: Pretreatment with Noncontingent Cocaine IV}

There was no statistically significant effect of drug [saline vs. noncontingent IV cocaine; $\mathrm{F}(1,7)=0.04$, NS]; however, there was an effect of injection interval [first vs. second interval; $\mathrm{F}(1,7)=30.39, p<.001]$ and a trend for a statistically significant interaction between drug and interval $[\mathrm{F}(1,7)=4.24, p<.1]$. Preplanned Newman-Keuls comparisons attributed the statistically significant effects to higher responses in the second interval compared to the first interval independent of drug pretreatment. Furthermore there were significantly fewer responses during the first interval after the noncontingent IV cocaine administration compared to the second interval after the noncontingent saline injection $(p<.5)$ (see Figure 3A). This last comparison is meaningful because under the saline condition the subjects received $0.25 \mathrm{mg}$ of cocaine IV contingently under the second-order schedule of reinforcement, the exact same dose that was noncontingently administered IV to the subjects before the first interval under the cocaine condition.

An ANOVA on the latencies to initiate responding indicated a statistically significant effect of drug $[\mathrm{F}(1,7)=$ $14.61, p<.01]$, no effect of injection interval $[F(1,7)=$ 3.11, NS], and a significant interaction between drug and interval $[\mathrm{F}(1,7)=7.04, p<.05]$. Posthoc comparisons attributed these effects to longer latencies during the first interval after the noncontingent IV cocaine administration compared to all three other intervals $(p<$ .05) (see Figure 3A).

\section{Experiment 3: Pretreatment with Contingent IV Cocaine Under a FR2 Reinforcement Schedule}

An ANOVA on the number of responses indicated no statistically significant effect of drug [saline vs. contingent IV cocaine; $F(1,6)=0.07, \mathrm{NS}]$, no effect of injection interval [first vs. second interval; $F(1,6)=3.18$, NS], and a trend for a statistically significant interaction between drug and interval $[\mathrm{F}(1,6)=5.43, p<.06]$. Preplanned Newman Keuls comparisons attributed the statistically significant interaction to the absence of a significant difference between responses for the first and the second interval after the contingent IV administration of cocaine under the FR2 schedule, in contrast to higher number of responses during the second interval compared to the first interval under baseline conditions $(p<$ .05) (see Figure 3B).

There were no statistically significant effects of drug $[\mathrm{F}(1,6)=0.55, \mathrm{NS}]$, injection interval $[\mathrm{f}(1,6)=1.47, \mathrm{NS}]$, or interaction between drug and interval $[\mathrm{F}(1,6)=1.07$, $\mathrm{NS}$ ] on the latencies to initiate responding (see Figure 3B).

In summary, the statistical analyses indicated that, in contrast to noncontingent IV cocaine (see Experiment 2 above), contingent administration of IV cocaine under the second-order schedule resulted in an increase in response numbers compared to responding during the first interval after pretreatment with saline. Further, consistent with the above results is the observation that contingent IV administration of cocaine under a FR2 schedule led to an absence of a difference in response numbers between the first and the second interval that is always observed under baseline conditions.

\section{Experiment 4: Pretreatment with Repeated Noncontingent IV Cocaine}

The one-way ANOVAs on the "high" noncontingent IV cocaine dose (i.e., $0.25 \mathrm{mg}$; training dose) data 


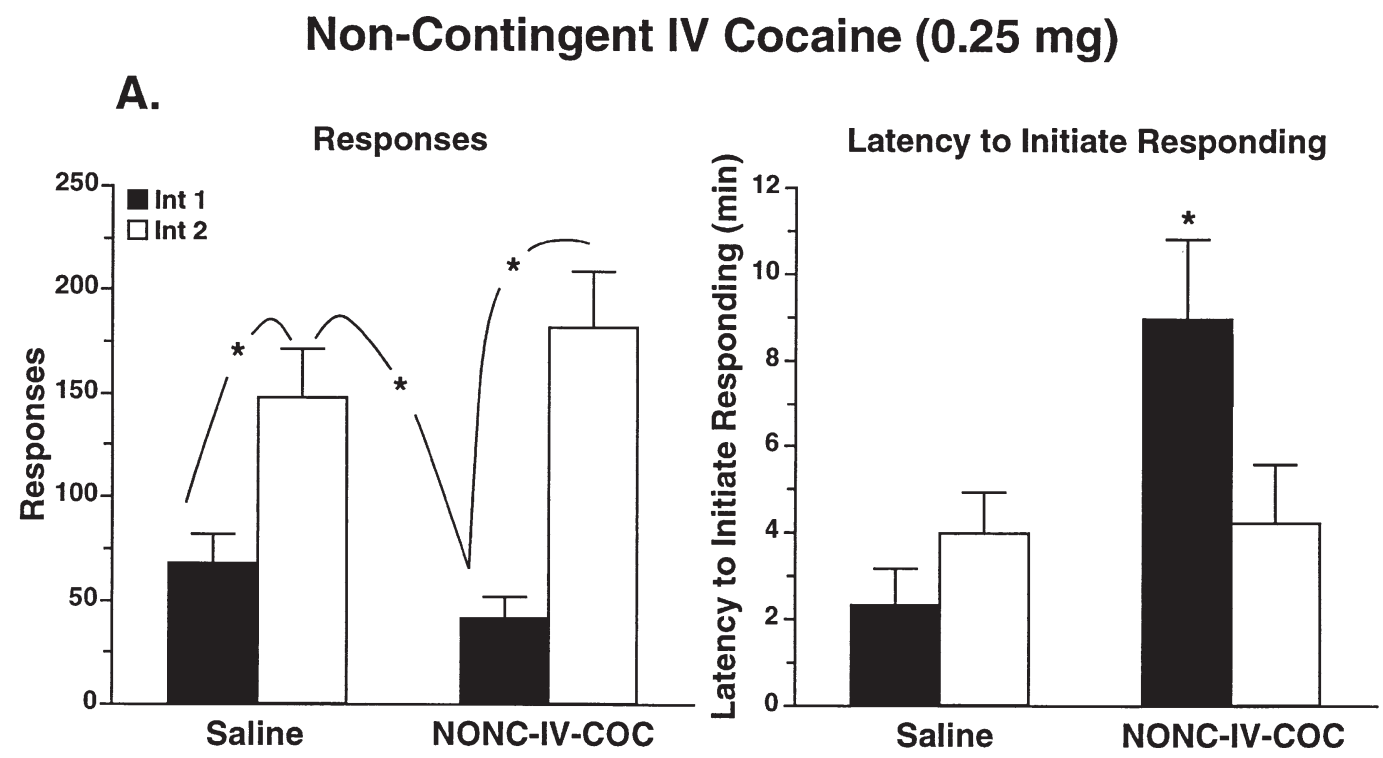

Contingent IV Cocaine $(0.25 \mathrm{mg})$

B.
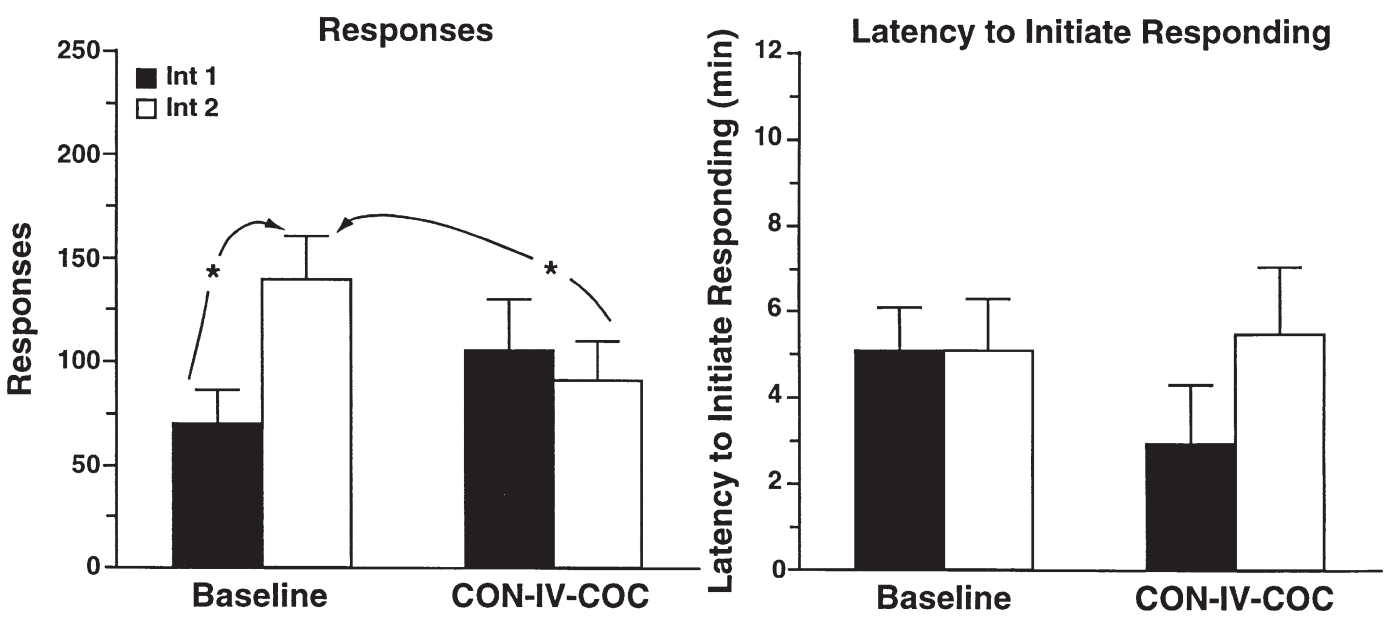

Figure 3. (A) Unlike contingent IV cocaine self-administered under the second-order reinforcement schedule (see second injection interval data under saline condition), pretreatment with noncontingent (i.e., experimenter-administered) I.V. cocaine $(0.25 \mathrm{mg}$; training dose) had no effect on responses but significantly increased the latency to initiate responding $(n=8)$ (see text for details). (B) Contingent IV cocaine $(0.25 \mathrm{mg} /$ injection), administered under a FR2 reinforcement schedule before the second-order schedule came into effect, resulted in a lack of difference in response numbers between the first and the second interval $(n=7)$. This pattern of responding was in contrast to higher response numbers during the second interval compared to the first interval under saline conditions. There were no statistically significant effects on the latency to initiate responding. This effect of contingent IV cocaine administered under the FR2 reinforcement schedule is similar to the effect of contingent IV cocaine administered under the second-order reinforcement schedule (see Figure 1), but differs from the effects of non-contingent IV experimenter-administered cocaine (see text for details).

had five levels (i.e., first interval data after saline injection; second interval data after saline injection; first interval data after $0.25 \mathrm{mg}$ of noncontingent IV cocaine for three consecutive days). The second interval data under the saline condition were included in these analyses because the self-administered dose of cocaine at the end of the first interval was identical to the dose experimenter-administered to the subjects just before the initiation of their daily session for 3 days. The ANOVA $[\mathrm{F}(4,28)=6.27, p<.001]$ and the posthoc comparisons $(p<.05)$ on response numbers indicated lower response numbers during the first inter- 
val after the noncontingent administration of the $0.25 \mathrm{mg}$ training dose of cocaine (for all 3 days during which this "high" noncontingent IV cocaine dose was administered) compared to the number of responses ob- served during the first interval after the noncontingent IV administration of saline $(p<.01)$, or the second interval after the contingent administration of the same dose of cocaine under the second-order reinforcement
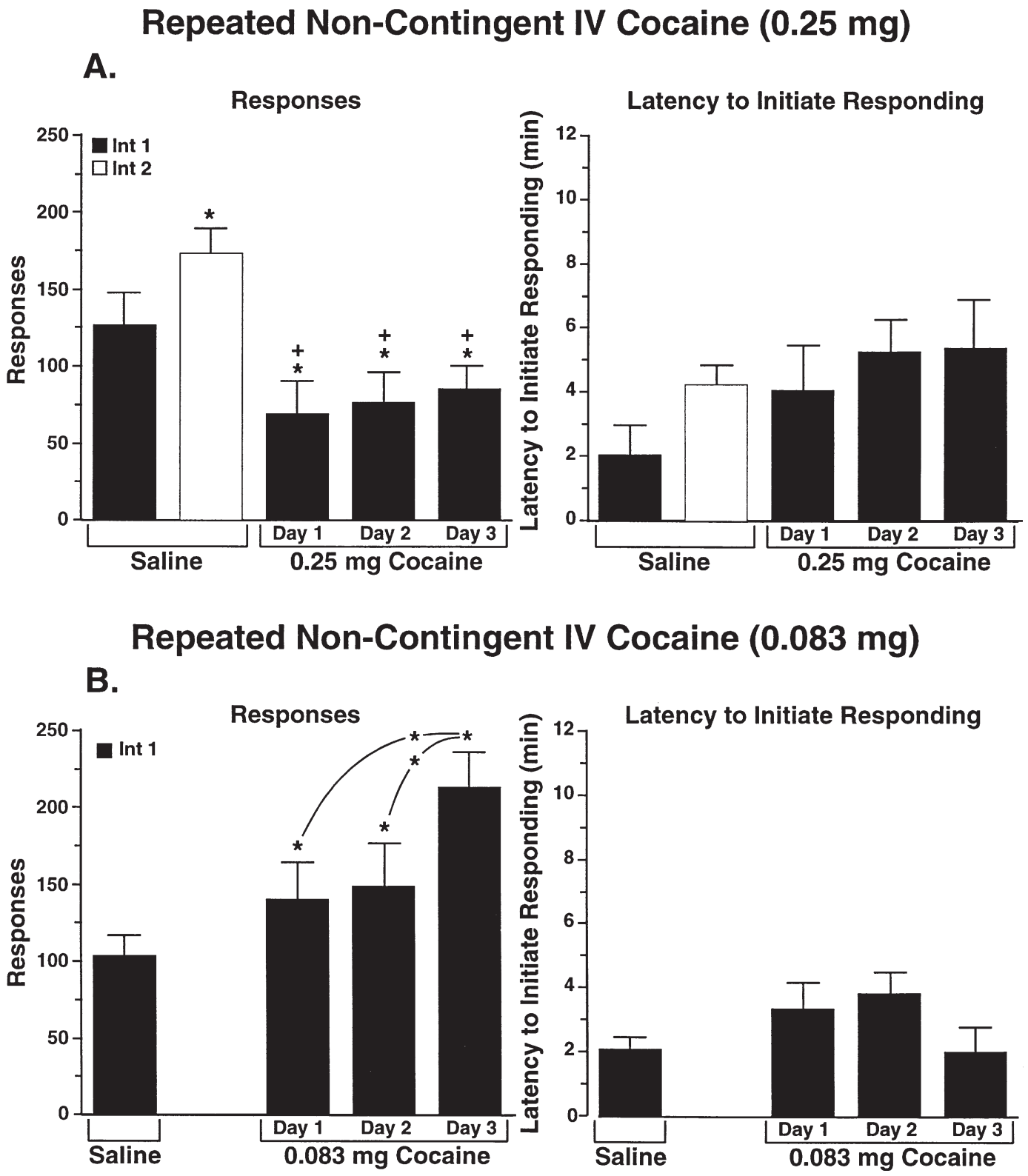

Figure 4. (A) Repeated (i.e., during three consecutive days) noncontingent IV administration of 0.25 mg cocaine hydrochloride (i.e., training dose) just before the initiation of the second-order session significantly decreased responses during the first interval compared to either the first or the second interval under baseline conditions (i.e., saline pretreatment). The comparison with the second interval is particularly relevant because in both cases the same cocaine dose was administered to the subject, in one case the administration was contingent and in the other case it was noncontingent. Asterisks indicate statistically significant differences from the first interval after noncontingent saline administration, while crosses indicate statistically significant differences from the second interval after noncontingent saline administration and contingent cocaine administration. There were no statistically significant effects of the repeated non-contingent injections of $0.25 \mathrm{mg}$ IV cocaine on the latency to initiate responding. (B) Repeated (i.e., during three consecutive days) noncontingent IV administration of $0.083 \mathrm{mg}$ cocaine hydrochloride (i.e., one third the training dose) just before the initiation of the second-order session significantly increased responses during the first interval compared to the first interval under baseline conditions (i.e., saline pretreatment). Asterisks indicate statistically significant differences from the first interval under baseline conditions, and between the three days after the noncontingent administration of cocaine, as indicated by the connecting lines. There were not statistically significant effects of the repeated non-contingent injections of $0.083 \mathrm{mg}$ IV cocaine on the latency to initiate responding. 
schedule $(p<.01)$ (see Figure 4A). A similar one-way ANOVA on the latencies to initiate responding indicated no statistically significant effect $[\mathrm{F}(4,28)=2.04$, NS] (see Figure 4A).

The one-way ANOVA on the "low" noncontingent cocaine dose (i.e., $0.083 \mathrm{mg}$; one third the training dose) data had four levels (i.e., first interval data after a saline injection, and first interval data after $0.083 \mathrm{mg}$ of cocaine for three consecutive days). The second interval data (after the noncontingent IV saline injection) were not included in these analyses because the noncontingently administered cocaine dose was different than the cocaine dose self-administered under the second-order reinforcement schedule; thus, any comparisons with this second interval data would not be meaningful. The ANOVA $[\mathrm{F}(3,15)=4.67, p<.05]$ and the posthoc comparisons on the number of responses indicated higher number of responses during the first interval after the noncontingent administration of $0.083 \mathrm{mg}$ of cocaine (for all 3 days during which this "low" noncontingent IV cocaine dose was administered) compared to the number of responses observed during the first interval after the noncontingent IV administration of saline $(p<$ .05). The Newman-Keuls comparisons also indicated that the third noncontingent administration of the 0.083 $\mathrm{mg}$ cocaine dose resulted in higher number of responses compared to the first and second noncontingent administration of the same dose $(p<.05)$ (see Figure 4B). A similar one-way ANOVA on the latencies to initiate responding indicated no statistically significant effects $[F(3,15)=2.50$, NS $]$ (see Figure $4 B$ ).

\section{DISCUSSION}

The results show that noncontingently (i.e., experimenter-) administered cocaine decreased responding under a second-order schedule of cocaine reinforcement and tended to increase the latency to initiate responding when IV doses equal to the training dose, or IP doses relatively high compared to the training cocaine dose, were administered. This effect of cocaine was independent of the route of administration (IV or IP), and did not change with repeated noncontingent IV administration of cocaine over three consecutive days. By contrast, contingently administered IV injections of cocaine resulted in increased responding for cocaine. This effect was primarily observed when cocaine was self-administered under the second-order schedule of reinforcement and did not change with repeated cocaine administrations, as indicated by steady baseline performance of the subjects during the second interval (i.e., after the first contingent administration of cocaine at the end of the first, drug-free interval) throughout the duration of each experiment. Further, there was a trend for increased responding after contingent IV administration of cocaine under the FR2 schedule of reinforcement. Finally, noncontingent administration of IV cocaine at a dose lower than the cocaine training dose also increased responding.

The results of the present studies indicate that even though drug-induced increases in drug-seeking behavior are a reliable and reproducible phenomenon, they occur only under certain conditions. At least three factors appear to determine whether drug injections will lead to drug-seeking behavior: (1) the size of the drug dose administered relative to the size of the drug dose used in training and maintenance of drug self-administration, (2) the type of behavioral paradigm used to assess drug-seeking behavior, and (3) whether the drug injection is administered contingently or noncontingently.

Accordingly, the results of the present studies indicate that noncontingent IV administration of a low cocaine dose relative to the training/maintenance dose increased drug-seeking behavior, as reflected in increased responding under a second-order schedule of reinforcement, whereas noncontingent IV administration of the training/maintenance dose of cocaine led to, what appeared to be, a satiation effect that was reflected in both a decrease in responding and a tendency for increased latency to initiate responding for cocaine. Studies with nonhuman primates using a second-order schedule of cocaine reinforcement have provided results entirely consistent with the present findings (Herling et al. 1979; Howell and Byrd 1995).

Furthermore, this dependence of the cocaine-induced increase in drug-seeking behavior on the magnitude of the cocaine dose administered relative to the training/ maintenance dose is consistent with some observations made in a procedure that assesses the reinstatement of drug-taking behavior after extinction. There, it was shown that even though all cocaine doses reinstated responding for cocaine under extinction conditions, higher doses increased the latency to reinitiate responding (deWit and Stewart 1981). In addition, results similar to those reported here also were obtained with another drug reinforcer, nicotine (Chiamulera et al. 1996), in a reinstatement paradigm similar to that used by deWit and Stewart (1981; it should be noted, however, that Chiamulera and colleagues used a between-session extinction/reinstatement procedure whereas the original deWit and Stewart studies used a within-session procedure). It was shown that the most effective nicotine doses for reinstatement of drug-taking behavior after extinction of nicotine self-administration were those lower than the training/maintenance nicotine dose, whereas the training/maintenance dose was ineffective in inducing reinstatement of nicotine self-administration (Chiamulera et al. 1996). Finally, in another procedure that measures drug-seeking behavior that is also dependent to some extent on the presentation of condi- 
tioned stimuli previously paired with cocaine injections, the effects of various doses of cocaine on responding for these cocaine-associated stimuli were characterized by an inverted U-shaped function, with doses higher than the training dose decreasing responding (Weissenborn et al. 1995; 1996). Therefore, in this context, it may be hypothesized that lower IP cocaine doses than those used in the present study may indeed increase responding in the second-order schedule of cocaine reinforcement.

Nevertheless, the majority of drug reinstatement studies have shown that doses even higher than the training/maintenance cocaine doses induce reinstatement after extinction in rats (Davis and Smith 1976; deWit and Stewart 1981; 1983; Stewart and Wise 1992; Comer et al. 1993; 1995; Shaham et al. 1994; Self et al. 1996), monkeys (Stretch and Gerber 1973; Gerber and Stretch 1975), and humans (Ludwig et al. 1974; Hodgson et al. 1979; Mirin et al. 1976; Meyer and Mirin 1979; Jaffe et al. 1989). Significant differences in the experimental history of the subjects between the second-order schedule and the reinstatement paradigms may explain these apparent discrepancies in experimental findings and may provide clues as to the factors that modulate drug-seeking behavior. The most important difference is that rats working under a second-order schedule of reinforcement in the present studies, unlike subjects tested in a reinstatement paradigm, had not undergone extinction. Future studies could address this hypothesis by examining whether extinction history may result in cocaine-induced reinstatement of responding under a second-order schedule of reinforcement independent of whether cocaine is administered contingently or noncontingently and of the size of cocaine dose relative to the training/maintenance dose. The different rates of baseline responding generated by the use of the two paradigms may also have contributed to the different results due to rate-dependency effects (Dews 1958; Sanger and Blackman 1976).

Taken together, the data presented here and the review of the literature indicate that the different behavioral measures provided by various paradigms, such as second-order schedules, FR5 schedules, and extinction procedures, reflect different aspects and phases of the drug use, abuse, craving, relapse, and dependence cycle. For instance, rates of responding under secondorder schedules of reinforcement allow the assessment of the amount of effort that an animal is willing to exert to gain access to drug-associated stimuli and to drug self-administration and may thus reflect drug-seeking behavior. Response rates under rich FR schedules, such as an FR5 schedule, appear to reflect primarily drugtaking behavior. As such, second-order and less demanding, in terms of response requirements, FR schedules assess different aspects of the positive reinforcing effects of drugs. Reinitiation of drug self-administration after several days of extinction may be a model of relapse (i.e., drug-seeking) after extinction rather than a model of drug-seeking without extinction and without a prolonged period of abstinence, a condition more closely reflected in performance under the second-order schedule of reinforcement. At this point, it is not clear what processes related to drug dependence are reflected by the daily within-session extinction procedure since a similar condition cannot be easily identified and studied in human drug users; thus, the predictive validity of such a model appears limited (Markou et al. 1993; Geyer and Markou 1995).

The third factor that appears to be important in determining whether a cocaine injection will induce drugseeking behavior is whether the injection is administered contingently or noncontingently. Noncontingent cocaine injections delivered either IP or IV led to a decrease in cocaine-seeking behavior, as reflected in a decrease in responding for cocaine and a tendency for longer latencies to initiate responding under the second-order schedule of cocaine reinforcement. By contrast, contingent IV administration of the same cocaine dose used in the noncontingent IV cocaine study led to increased drug-seeking behavior that was reflected in increased responding for cocaine during the next fixed interval (see interval 2 data under saline or baseline conditions in Figures 3A and 3B). This effect of contingently administered cocaine was primarily observed when cocaine was self-administered under the secondorder schedule of reinforcement, although a trend for such an effect also was seen even under a minimal FR 2 response requirement. Further, it was demonstrated that these differences in the effects of contingent versus noncontingent cocaine on drug-seeking behavior did not change with repeated cocaine administrations, independent of whether the administration was contingent (i.e., consistently higher responses during the second interval) or noncontingent (see Figure 4A). Thus, the response-reducing effects of noncontingent cocaine administration cannot be attributed to potentially disruptive effects of unexpected cocaine injections on the subjects' performance. Taken together, these results indicate the importance of contingency in determining some of the effects of cocaine on cocaine-seeking behavior. It should be noted that related factors that cannot be readily manipulated experimentally also may contribute to the differences in the effects of contingent versus noncontingent cocaine on drug-seeking behavior. Such factors include potential "warm-up" effects associated with the fact that contingent drug-administration requires initiation of drug-seeking. Thus, the constellation of factors that comprises contingent drug administration should be considered as the variable that contributes to increased drug-seeking behavior.

Future studies should examine whether the effects of cocaine seen in the present studies are specific to co- 
caine-seeking behavior or whether similar effects are seen in the seeking of other reinforcers, such as food. Few studies have examined the effects of cocaine on performance under second-order schedules with a nondrug as the primary reinforcer. One study in nonhuman primates indicated that experimenter-administered intramuscular injections of cocaine increased responding for food under a second-order schedule or reinforcement (Goldberg et al. 1981). Studies using other schedules have indicated increases, decreases or no effects in responding for food after cocaine administration (D'Mello et al. 1981; Hughes et al. 1996: Glowa and Fantegrossi 1997; Heyser et al. 1997; Panlilio et al. 1998). Based on the hypothesis that drugs of abuse may in part act through the same neurobiological mechanisms that mediate the incentive-motivational properties of "natural" reinforcers (for reviews, see Fibiger and Phillips 1988; Koob and Bloom 1988; Altman et al. 1996), it is perhaps unlikely that differential effects of manipulations will be seen depending on the modality of the primary reinforcer.

In conclusion, the results of the present studies have shown that noncontingent experimenter-administered doses of cocaine result in a satiation-like effect in an animal model of drug-seeking behavior when the doses of cocaine administered were similar to or higher than the training/maintenance dose of cocaine. By contrast, contingent self-administered cocaine and noncontingent administration of cocaine doses lower than the training/maintenance dose result in increased drug-seeking behavior, which may represent an operational measure of drug craving (Markou et al. 1993). Finally, the present studies indicate the feasibility of conducting such experiments in rodents, even though second-order schedules of IV drug reinforcement have been used primarily in primates. As such, the use of these second-order schedules of reinforcement may allow investigation of the neurobiological mechanisms underlying drugseeking behavior while the subject is in an undrugged state, thereby providing insights into the development of behavioral or pharmacological therapeutic interventions that would prevent cue-induced drug craving, drug-seeking, and relapse to drug-taking.

\section{ACKNOWLEDGMENTS}

The authors thank Drs. Trevor W. Robbins and George F. Koob for their continued input and support during the conduct of this project. The authors also thank Mike Arends for his assistance with library and computer literature searches, and editorial assistance, and Melpomeni Zapadi for assistance with data recording. This is publication number 11151-NP from The Scripps Research Institute. Portions of the data presented herein were presented at the 1996 meetings of the European Behavioural Pharmacology Society (Markou et al. 1996a; Arroyo et al. 1996a) and the Society for Neuroscience
(Markou et al. 1996b; Arroyo et al. 1996b). This work was supported by a Medical Research Council U.K. Programme grant to BJE (No. 9537855). AM was supported by a National Institute on Drug Abuse U.S.A. Research Scientist Award (K21DA00213).

\section{REFERENCES}

Altman J, Everitt BJ, Glautier S, Markou A, Nutt D, Oretti R, Phillips GD, Robbins TW (1996): The biological, social and clinical bases of drug addiction: commentary and debate. Psychopharmacol 125:285-345

Arroyo M, Markou A, Robbins TW, Everitt BJ (1996a): Establishment of a second-order schedule of intravenous cocaine reinforcement in rats: effects of contingent, noncontingent and free-access to cocaine. Behav Pharmacol 7(Suppl 1):3

Arroyo M, Markou A, Robbins TW, Everitt BJ (1996b): Drugseeking behaviour measured using a second-order schedule of I.V. cocaine reinforcement: effects of withdrawal from free-access to cocaine. Soc Neuroscience Abstr 22:925

Arroyo M, Markou A, Robbins TW, Everitt BJ (1998): Acquisition and maintenance of intravenous cocaine self-administration under a second-order schedule of reinforcement in rats: Effects of conditioned cues and continuous access to cocaine. Psychopharmacol 140:331-344

Bozarth MA (Ed) (1987): Methods of Assessing the Reinforcing Properties of Abused Drugs. New York, SpringerVerlag

Carroll ME (1985): Performance maintained by orally delivered phencyclidine under second-order, tandem and fixed interval schedules in food-satiated and fooddeprived rhesus monkeys. J Pharmacol Exp Ther 232: 351-359

Chiamulera C, Borgo C, Falchetto S, Valerio E, Tessari M (1996): Nicotine reinstatement of nicotine self-administration after long-term extinction. Psychopharmacol 127(2):102-107

Childress AR, McLellan AT, Ehrman R, O'Brien CP (1988): Classically conditioned responses in opioid and cocaine dependence: a role in relapse? NIDA Res Monogr 84:25-43

Childress A, McLellan AT, O’Brien CP (1986): Abstinent opiate abusers exhibit conditioned craving, conditioned withdrawal and reductions in both through extinction. Br J Addict 81:655-660

Comer SD, Lac ST, Curtis LK, Carroll ME (1993): Effects of buprenorphine and naltrexone on reinstatement of cocaine-reinforcement responding in rats. J Pharmacol Exp Ther 267(3):1470-1477

Comer SD, Lac ST, Wyvell CL, Curtis LK, Carroll ME (1995): Food deprivation affects extinction and reinstatement of responding in rats. Psychopharmacol 121:150-157

Corrigall WA, Coen KM (1989): Fixed interval schedules for drug self-administration in the rat. Psychopharmacol 99:136-139

Davis WM, Smith SG (1976): Role of conditioned reinforcers in the initiation, maintenance and extinction of drugseeking behavior. Pavlovian J Biol Sci 11(4):222-236 
de Boer MC, Schippers GM, van der Staak CPF (1993): Alcohol and social anxiety in women and men: pharmacological and expectancy effects. Addict Behav 18:117-126

deWit H, Stewart J (1981): Reinstatement of cocaine-reinforced responding in the rat. Psychopharmacol 75:134-143

deWit H, Stewart J (1983): Drug reinstatement of heroinreinforced responding in the rat. Psychopharmacol 79:29-31

D'Mello GD, Goldberg DM, Goldberg SR, Stolerman IP (1981): Conditioned taste aversion and operant behavior in rats: effects of cocaine, apomorphine and some long-acting derivatives. J Pharmacol Exp Ther 219(1):60-68

Dews PB (1958): Studies on behavior. IV. Stimulant actions of methamphetamine. J Pharmacol Exp Ther 122:137-147

Dixon WJ (Ed) (1992): BMDP Statistical Software Manual. Berkeley, University of California Press

Fibiger HC, Phillips AG (1988): Mesocorticolimbic dopamine systems and reward. Ann NY Acad Sci 537:206-215

Fischman MW, Schuster CR, Hatano Y (1983): A comparison of the subjective and cardiovascular effects of cocaine and lidocaine in humans. Pharmacol Biochem Behav 18:123-127

Fry W, Kelleher RT, Cook L (1960): A mathematical index of performance on fixed-interval schedules of reinforcement. J Exp Anal Behav 3:193-199

Gerber GJ, Stretch R (1975): Drug-induced reinstatement of extinguished self-administration behavior in monkeys. Pharmacol Biochem Behav 3(6):1055-1061

Geyer MA, Markou A (1995): Animal models of psychiatric disorders. In: Bloom FE and Kupfer DJ (eds), Psychopharmacology: The Fourth Generation of Progress. New York, Raven Press, pp 787-798

Glowa JR and Fantegrossi WE (1997): Effects of dopaminergic drugs on food- and cocaine-maintained responding. IV. Continuous infusions. Drug Alcohol Depend 45(12):71-79

Goldberg SR (1973): Comparable behavior maintained under fixed-ratio and second-order schedules of food presentation, cocaine injection or $\mathrm{d}$-amphetamine injection in the squirrel monkey. J Pharmacol Exp Ther 186:18-30

Goldberg SR, Gardner ML (1981): Second-order schedules: extended sequences of behavior controlled by brief environmental stimuli associated with drug-administration. NIDA Res Monogr 37:241-270

Goldberg SR, Hoffmeister F, Schlichting UU, Wuttke W (1971): A comparison of pentobarbital and cocaine self-administration in rhesus monkeys: effect of dose and fixedratio parameter. J Pharmacol Exp Ther 179:277-283

Goldberg SR, Kelleher RT, Goldberg DM (1981): Fixed-ratio responding under second-order schedules of food presentation or cocaine injection. J Pharmacol Exp Ther 218:271-281

Goldberg SR, Spealman RD, Kelleher RT (1979): Enhancement of drug-seeking behavior by environmental stimuli associated with cocaine or morphine injections. Neuropharmacol 18:1015-1017

Goldberg SR, Tang AH (1977): Behavior maintained under second-order schedules of intravenous morphine injec- tion in squirrel and rhesus monkeys. Psychopharmacol 51:235-242

Heyser CJ, McDonald JS, Beauchamp V, Koob GF, Gold LH (1997): The effects of cocaine on operant responding for food in several strains of mice. Psychopharmacol 132(2):202-208

Henningfield JE, Nemeth-Coslett R, Katz JL, Goldberg SR (1988): Intravenous cocaine-self-administration by human volunteers: second-order schedules of reinforcement. NIDA Res Monogr 84:266-273

Herling S, Downs DA, Woods JH (1979): Cocaine, d-amphetamine, and pentobarbital effects on responding maintained by food or cocaine in rhesus monkeys. Psychopharmacol 64:261-269

Hodgson R, Rankin H, Stockwell T (1979): Alcohol dependence and the priming effect. Behav Res Ther 17:379-387

Howell LL, Byrd LD (1991): Characterization of the effects of cocaine and GBR 12909, a dopamine uptake inhibitor, on behavior in the squirrel monkey. J Pharmacol Exp Ther 258(1):178-185

Howell LL, Byrd LD (1995): Serotonergic modulation of the behavioral effects of cocaine in the squirrel monkey. J Pharmacol Exp Ther 275(3):1551-1559

Hull JG, Bond CF Jr (1986): Social and behavioral consequences of alcohol consumption and expectancy: a meta-analysis. Psychol Bull 99(3):347-360

Hughes CE, Pitts RC, Branch MN (1996): Cocaine and food deprivation: effects of food-reinforced fixed-ratio performance in pigeons. J Exp Anal Behav 65(1):145-158

Jaffe JH, Cascella NG, Kumor KM, Sherer MA (1989): Cocaineinduced cocaine craving. Psychopharmacol 97: 59-64

Johanson CE (1982): Behavior maintained under fixed-interval and second-order schedules of cocaine or pentobarbital in rhesus monkeys. J Pharmacol Exp Ther 221(2): 384-393

Johanson CE, Fischman MW (1989): The pharmacology of cocaine related to its abuse. Pharmacol Rev 41(1):3-52

Katz JL (1979): A comparison of responding maintained under second-order schedules of intramuscular cocaine injection or food presentation in squirrel monkeys. J Exp Anal Behav 32:419-431

Kelleher RT (1975): Characteristics of behavior controlled by schedules injections of drugs. Pharmacol Rev 27:307-323

Kelleher RT, Goldberg SR (1977): Fixed-interval responding under second-order schedules of food presentation or cocaine injection. J Exp Anal Behav 28:221-231

Koob GF, Bloom FE (1988): Cellular and molecular mechanisms of drug dependence. Science 242:715-723

Laberg JC (1986): Alcohol and expectancy: subjective, psychophysiological and behavioral responses to alcohol stimuli in severely, moderately and non-dependent drinkers. Br J Addict 81:797-808

Lamb RJ, Preston KL, Schindler CW, Meisch RA, Davis F, Katz JL, Henningfield JE, Goldberg SR (1991): The reinforcing and subjective effects of morphine in postaddicts: a dose-response study. J Pharmacol Exp Ther 259(3):1165-1173

Levine DG (1974): "Needle freaks": compulsive self-injection by drug users. Am J Psychiatry 131:297-300 
Liebman JM, Cooper SJ (Eds) (1989): The Neuropharmacological Basis of Reward. New York, Oxford University Press

Ludwig AM (1986): Pavlov's "bells" and alcohol craving. Addict Behav 11:87-91

Ludwig AM, Wikler A, Stark LH (1974): The first drink: psychobiological aspects of craving. Arch Gen Psychiatry 30:539-547

Markou A, Arroyo M, Everitt BJ (1996a): Drug craving: utility of animal models such as second-order schedules of reinforcement. Behav Pharmacol 7(Suppl 1):63

Markou A, Arroyo M, Everitt BJ (1996b): Effects of cocaine and dopamine agonists on cocaine-seeking behavior in rats: a second-order schedule of reinforcement. Soc Neurosci Abstr 22:925

Markou A, Koob GF (1992): Construct validity of a self-stimulation threshold paradigm: Effects of reward and performance manipulations. Physiol Behav 51:11-119

Markou A, Weiss F, Gold LH, Caine SB, Schulteis G, Koob GF (1993): Animal models of drug craving. Psychopharmacol 112:163-182

McLellan AT, Childress AR, Ehrman R, O'Brien CP, Pashko $S$ (1986): Extinguishing conditioned responses during opiate dependence treatment: turning laboratory findings into clinical procedures. J Subst Abuse Treat 3:33-40

Mello NK, Mendelson JH (1985): Operant acquisition of marihuana by women. J Pharmacol Exp Ther 235(1): $162-171$

Mello NK, Mendelson JH, Palmieri S, Lex BW, Teoh SK (1990): Operant acquisition of alcohol by women. J Pharmacol Exp Ther 253(1):237-245

Mello NK, Negus SS, Lukas SE, Mendelson JH, Sholar JW, Drieze J (1995): A primate model of polydrug abuse: Cocaine and heroin combinations. J Pharmacol Exp Ther 274(3):1325-1337

Meyer RE, Mirin SM (1979): The Heroin Stimulus: Implications for a Theory of Addiction. New York, Plenum Medical Book Company

Mirin SM, Meyer RE, McNamee HB, McDougle M (1976): Psychopathology, craving, and mood during heroin acquisition: an experimental study. Int $\mathrm{J}$ Addict 11(3):525-544

Mitchell SH, Laurent CL, de Wit H (1996): Interaction of expectancy and the pharmacological effects of d-amphetamine: subjective effects of self-administration. Psychopharmacology 125:371-378

Negus SS, Mello NK, Portoghese PS, Lukas SE, Mendelson JH (1995): Role of delta opioid receptors in the reinforcing and discriminative stimulus effects of cocaine in rhesus monkeys. J Pharmacol Exp Ther 273(3):1245-1256

O'Brien CP, Childress AR, McLellan AT, Ehrman R (1990): Integrating systematic cue exposure with standard treatment in recovering drug dependent patients. Addict Behav 15:355-365

O'Brien CP, Childress AR, McLellan A, Ehrman R (1992): A learning model of addiction. In O'Brien CP, Jaffe JH (eds), Addictive States. New York, Raven Press, pp 157-177

O'Brien CP, Ehrman RN, Ternes JW (1984): Classical condi- tioning in opiate dependence. NIDA Res Monogr 49: $35-46$

Panlilio LV, Goldberg SR, Gilman JP, Jufer R, Cone EJ, Schindler CW (1998): Effects of delivery rate and noncontingent infusion of cocaine self-administration in rhesus monkeys. Psychopharmacol 137(3):253-258

Ranaldi R, Roberts DCS (1996): Initiation, maintenance and extinction of cocaine self-administration with and without conditioned reward. Psychopharmacol 128:89-96

Sanger DJ, Blackman DE (1976): Rate-dependent effects of drugs: A review of the literature. Pharmacol Biochem Behav 4:73-83

Self DW, Barnhart WJ, Lehman DA, Nestler EJ (1996): Opposite modulation of cocaine-seeking behavior by $\mathrm{D}_{1}$ - and $\mathrm{D}_{2}$-like dopamine receptor agonists. Science 271:15861589

Shaham Y, Rodaros D, Stewart J (1994): Reinstatement of heroin-reinforced behavior following long-term extinction: implications for the treatment of relapse to drug taking. Behav Pharmacol 5:360-364

Siegel S (1956): Nonparametric Statistics for the Behavioral Sciences. New York, McGraw-Hill

Spealman RD, Bergman J, Madras BK (1991): Self-administration of the high-affinity cocaine analog 2beta-carbomethoxy-3beta-(4-fluorophenyl)tropane. Pharmacol Biochem Behav 39:1011-1013

Spear DJ, Katz JL (1991): Cocaine and food as reinforcers: effects of reinforcer magnitude and response requirement under second-order fixed-ratio and progressiveratio schedules. J Exp Anal Behav 56:261-275

Spear DJ, Muntaner C, Goldberg SR, Katz JL (1991): Methohexital and cocaine self-administration under fixedratio and second-order schedules. Pharmacol Biochem Behav 38:411-416

Stewart J, Wise RA (1992): Reinstatement of heroin selfadministration habits: Morphine prompts and naltrexone discourages renewed responding after extinction. Psychopharmacol 108:79-84

Stretch R, Gerber GJ (1973): Drug-induced reinstatement of amphetamine self-administration behavior in monkeys. Can J Psychol 27:168-177

Weissenborn R, Deroche V, Koob GF, Weiss F (1996): Effects of dopamine agonists and antagonists on cocaineinduced operant responding for a cocaine-associated stimulus. Psychopharmacol 126:311-322

Weissenborn R, Yackey M, Koob GF, Weiss F (1995): Measures of cocaine-seeking behavior using a multiple schedule of food and drug self-administration in rats. Drug Alcohol Depend 38:237-246

Wikler A (1971): Some implications of conditioning theory for problems of drug abuse. Behav Sci 16:92-97

Whitelaw RB, Markou A, Robbins TW, Everitt BJ (1996): Excitotoxic lesions of the basolateral amygdala impair the acquisition of cocaine-seeking behaviour under a second-order schedule of reinforcement. Psychopharmacol 127:213:224

Winer BJ (1971): Statistical Principles in Experimental Design. New York, McGraw-Hill 